\title{
Las dimensiones urbanas en el desarrollo rural
}

\section{Alexander Schejtman}

Organización de las

Naciones Unidas

para la Alimentación

y la Agricultura (FAO),

Santiago de Chile
En el presente artículo se hacen algunos alcances a la necesidad de reenfocar las políticas de desarrollo rural y alivio de la pobreza. Después de señalar las limitaciones de los enfoques tradicionales de dichas políticas, se plantea, entre otras consideraciones, la necesidad de incorporar la dimensión territorial en su diseño, y se pasa revista al contexto macroeconómico y el entorno sectorial agrícola que condicionan las políticas, haciendo hincapié en la heterogeneidad estructural y en la presencia de mercados imperfectos (sección I). En seguida se destacan las limitaciones de los enfoques tradicionales de desarrollo rural y la necesidad de reconsiderar el papel de las migraciones rural-urbanas (sección II). Se abordan luego los vínculos entre la cuestión urbana y el desarrollo rural, destacando la necesidad de aprovechar las potencialidades de una correcta articulación entre los pequeños núcleos urbanos y su entorno agrícola (sección III). Y, por último, se examinan algunos aspectos relacionados con las instituciones y se pone de relieve la necesidad de innovaciones institucionales que permitan la participación y la concertación público-privada a escala local (sección IV). 


\section{I}

\section{El contexto global y sectorial}

Asistimos actualmente a un proceso de cambios significativos en el funcionamiento de las economías de la región. La desregulación de los mercados, la liberalización del sector externo, la privatización de las empresas públicas y el ajuste fiscal han ido acompañados en muchos países por procesos de descentralización de la gestión pública, elección popular de alcaldes y gobernadores y delegación de competencias a municipios, provincias o estados federales, y han significado transferencias crecientes de recursos y de responsabilidades en materia de educación, salud e incluso de desarrollo a las economías locales. Se plantea entonces la necesidad de reexaminar las estrategias tradicionales de desarrollo rural, de modo de avanzar hacia un enfoque de tipo espacial que considere como contexto de la política los vínculos entre los núcleos urbanos intermedios y su entorno agrícola-rural.

\section{El contexto macroeconómico}

En lo interno, como resultado de las políticas de ajuste estructural aplicadas con mayor o menor intensidad en todos los países, se están redefiniendo las reglas del juego que habían regido las economías de la región por varias décadas y a las que los agentes económicos se habían habituado. El abandono de las prácticas proteccionistas y una creciente apertura al comercio exterior; la reducción del peso relativo del sector público y la privatización de empresas de propiedad del Estado; la subordinación de las políticas sectoriales a los equilibrios macroeconómicos y el sesgo hacia la producción de bienes exportables, entre otros, son fenómenos cuyos efectos sobre el crecimiento económico, la equidad distributiva y la sustentabilidad a largo plazo resultan todavía impredecibles.

En el sector agropecuario, y en lo inmediato, las nuevas condiciones han sido aprovechadas fundamentalmente por empresas con tierras más aptas para la producción de bienes exportables y con capacidad de acceder al crédito, a la tecnología y a la información sobre las condiciones de los mercados interno y externo, dando lugar en varios países a un significativo crecimiento de las exportaciones, sobre todo en rubros no tradicionales. Sin negar los elementos positivos de esta dinámica, ella presenta, sin embargo, un riesgo potencial que es preciso evitar con medidas adecuadas: el de acentuar el carácter excluyente y polarizador que ha caracterizado el proceso de modernización agraria de la región en los últimos decenios, concentrado en determinados productos, así como en algunas regiones $\mathrm{y}$ en los productores medianos y grandes.

Los cambios en el entorno internacional y en las reglas del juego internas de las economías de la región hacen que el incremento sostenido de la competitividad $^{1}$ y su corolario, la amplia difusión del progreso técnico, hayan pasado a ser condición necesaria para el crecimiento y para la propia viabilidad de las unidades productivas. Estos desafíos, en el caso de la agricultura de los países de la región, se plantean en un contexto particular en lo que se refiere a sus estructuras agrarias y al funcionamiento de los mercados rurales.

\section{El contexto sectorial: heterogeneidad, merca- dos imperfectos y costos de transacción}

Dos son los principales factores estructurales que determinan el funcionamiento del sector agropecuario de la gran mayoría de los países de la región: la heterogeneidad de la estructura productiva y la presencia o inexistencia de fallas en los mercados de crédito, seguros, tecnología, información, trabajo y otros.

Una de las características comunes a la gran mayoría de los países, derivadas del período de transición de la hacienda a la empresa agrícola capitalista, es la coexistencia de una agricultura empresarial o capitalista y una campesina que, por las características a las que haremos referencia más adelante, plantea problemas complejos para el diseño de las políticas de incentivos y de difusión del progreso técnico, condición necesaria para la competitividad. Mientras en estructuras homogéneas un determinado estímulo o una opción tecnológica válida (es decir, coherente con las dotaciones relativas de recursos de los productores) lo

\footnotetext{
${ }^{1}$ En términos simples y en el caso de los pequeños productores y de los trabajadores rurales con poca o ninguna tierra, ser "competitivo" significa mejorar en algún grado los niveles de ingreso neto derivados del conjunto de sus actividades.
} 
es para la gran mayoría de las unidades productivas, en las estructuras bimodales un incentivo o una opción tecnológica considerada adecuada para la gran empresa agrícola moderna probablemente no lo sea para el sector de agricultura familiar, enfrentada al mismo conjunto de precios relativos.

\section{a) Contrastes en la lógica interna de manejo}

Aun a riesgo de reiterar hechos conocidos, es importante señalar que tanto la evidencia empírica como un cierto fundamento teórico permiten sostener que existirían marcadas diferencias en lo que hemos llamado la lógica interna de manejo o los criterios con que uno y otro tipo de agricultura abordan las decisiones de qué, cuánto, cómo y para qué producir, las que tienen gran relevancia para el diseño de estrategias o políticas que pretendan influir en el comportamiento y desarrollo del sector.

Las diferencias de comportamiento entre una y otra forma de organización se sintetizan en el cuadro $1,{ }^{2}$ y aunque no corresponde examinar aquí cada una de ellas, cabe poner de relieve los contrastes en la naturaleza de la fuerza de trabajo y en la forma de internalizar el riesgo, porque inciden de manera directa en los patrones de multiactividad característicos de las unidades familiares campesinas.

El que exista un margen de fuerza de trabajo no transferible en la agricultura familiar (trabajo de los hijos y de la mujer o de otros familiares no remunerados, tiempo "libre" del jefe) significa que ese margen sólo es capaz de crear valor al interior de esa estructura - es decir, no existe otro espacio de valorización de ese tiempo de trabajo disponible-, mientras que, por contraste, la empresa agrícola depende de mano de obra asalariada que contrata en el mercado. ${ }^{3}$

Las consideraciones sobre riesgo también son incorporadas de modo diferente en los criterios de manejo pues, mientras para un empresario es razonable inclinarse a asumir una alternativa de mayor riesgo si ésta va compensada por una mayor ganancia, el pequeño productor tiende a evitar la opción más riesgosa, por importante que sea el ingreso esperado de un resultado positivo, ante la amenaza a su susten-

\footnotetext{
2 Véase una presentación del fundamento teórico de lo que aquí se señala en Schejtman (1980) y Figueroa (1981).

${ }^{3}$ En otro trabajo destacamos que esta situación permitía que, bajo ciertas condiciones y en productos con uso intensivo de mano de obra y sin economías de escala, estas unidades fueran potencialmente competitivas con las que dependen exclusiva o principalmente de mano de obra asalariada (Schejtman, 1998).
}

tabilidad familiar y productiva que surgiría de un resultado adverso. ${ }^{4}$

Estos contrastes de lógica de manejo implican que las políticas orientadas a inducir determinados comportamientos de parte de uno y otro tipo de productores no pueden ser las mismas y que, por lo tanto, se requieren diseños específicos y diferenciados para uno y otro sector. Así por ejemplo, y simplificando, un conjunto predecible de los principales precios macroeconómicos (tasa de interés, tipo de cambio, tasa de salarios) junto a medidas que morigeren sus efectos no deseados, pueden ser suficientes para determinar los comportamientos de la agricultura empresarial moderna; sin embargo, para inducir determinados cambios en la pequeña agricultura se necesita un conjunto más complejo de medidas que vayan más allá de simples ajustes a los efectos de los precios macro.

De los cambios experimentados en las reglas que rigen el funcionamiento de las economías de la región y de las consideraciones anteriores sobre la heterogeneidad sectorial se derivan dos tipos de desafíos, que suponen estrategias y políticas distintas para uno y otro tipo de agricultura. En primer lugar está el que se plantea a la agricultura empresarial; ésta corre el riesgo de ver erosionadas las bases de su competitividad si no es capaz de incorporar el progreso técnico en los eslabones más críticos de sus cadenas de producción, dado que las ventajas derivadas del costo de la mano de obra y de la dotación de recursos naturales se van desgastando como fuentes de competitividad. En segundo lugar está el desafío de formular opciones para el heterogéneo sector campesino (pequeños agricultores y familias rurales con poca o ninguna tierra) que corren el riesgo, algunos, de perder toda condición de productores y los más, de incrementar la magnitud y profundidad de la pobreza rural y urbana, si no logran articularse con procesos que mejoren las opciones de empleo de su fuerza de trabajo; esto debe hacerse con políticas diferenciadas por tipo de unidad a partir de tipologías de productores (o unidades familiares) que, junto con dar cuenta de dicha heterogeneidad, sean funcionales al diseño e implementación de las políticas. La funcionalidad supone que los criterios de clasificación incluyan elementos relativos a las formas de

\footnotetext{
4 "Un próspero granjero americano puede preferir una probabilidad de $50 \%$ de obtener 5000 o 10000 dólares a la certeza de obtener 7 000. Un campesino hindú, ante la probabilidad de obtener 1000 rupias contra la certeza de 700 con los que apenas alimenta a su familia, no puede poner x muy por debajo de 700" (Lipton, 1968, p. 335).
} 
CUADRO 1

Diferencias en las características de la agricultura campesina y de la empresarial

\begin{tabular}{|c|c|c|}
\hline Atributos & Agricultura campesina & Agricultura empresarial \\
\hline Objetivo de la producción & $\begin{array}{l}\text { Reproducción de la familia y de la unidad } \\
\text { de producción }\end{array}$ & $\begin{array}{l}\text { Maximización de la tasa de ganancia y de la } \\
\text { acumulación de capital }\end{array}$ \\
\hline Origen de la fuerza de trabajo & $\begin{array}{l}\text { Fundamentalmente familiar y, en ocasiones, } \\
\text { intercambio recíproco con otras unidades; } \\
\text { excepcionalmente asalariada en cantidades } \\
\text { marginales }\end{array}$ & Asalariada \\
\hline $\begin{array}{l}\text { Compromiso laboral del jefe con la mano de } \\
\text { obra }\end{array}$ & Absoluto & Inexistente, salvo por obligación legal \\
\hline Tecnología & $\begin{array}{l}\text { Uso intensivo de mano de obra, baja densi- } \\
\text { dad de "capital" y de insumos comprados por } \\
\text { jornada de trabajo }\end{array}$ & $\begin{array}{l}\text { Mayor densidad de capital por activo y } \\
\text { mayor proporción de insumos comprados en } \\
\text { el valor del producto final }\end{array}$ \\
\hline Destino del producto y origen de los insumos & Parcialmente mercantil & Mercantil \\
\hline Criterio de intensificación del trabajo & $\begin{array}{l}\text { Máximo producto total, aun a costa del des- } \\
\text { censo del producto medio. Límite: producto } \\
\text { marginal cero }\end{array}$ & $\begin{array}{l}\text { Productividad marginal mayor que el sala- } \\
\text { rio }\end{array}$ \\
\hline Riesgo e incertidumbre & $\begin{array}{l}\text { Evasión no probabilística: algorritmo de } \\
\text { sobrevivencia }\end{array}$ & $\begin{array}{l}\text { Internalización probabilística buscando tasas } \\
\text { de ganancia proporcionales al riesgo }\end{array}$ \\
\hline Carácter de la fuerza de trabajo & $\begin{array}{l}\text { Fuerza valorizada de trabajo intransferible o } \\
\text { marginal }\end{array}$ & $\begin{array}{l}\text { Sólo emplea fuerza de trabajo transferible en } \\
\text { función de su calificación }\end{array}$ \\
\hline Componentes del ingreso o producto neto & $\begin{array}{l}\text { Producto o ingreso familiar indivisible y } \\
\text { realizado parcialmente en especie }\end{array}$ & $\begin{array}{l}\text { Salario, renta y ganancias, exclusivamente } \\
\text { pecuniarias }\end{array}$ \\
\hline
\end{tabular}

Fuente: Schejtman (1980).

inserción de estas unidades en la economía y que el número de categorías no supere al que pueda abarcar la capacidad de gestión del aparato público. ${ }^{5}$

\section{b) Los mercados rurales}

La actividad agrícola en general y la de los pequeños productores en particular funcionan en un ámbito en que el comportamiento de los mercados de crédito, seguro, tecnología, información, trabajo — como anotan Sadoulet y De Janvry (1995, p. 254)— está muy lejos del modelo de una "economía walrasiana estándar" que postula que todos los mercados existen, incluyendo los de crédito y de riesgo, y que los precios de equilibrio determinados por estos mercados se aplican por igual a todos los participantes. En los países de menor desarrollo hay muchas fallas de los mer-

${ }^{5}$ Véanse en CEPAL (1982), De Janvry, Gordillo y Sadoulet (1997) y FAO (1997), algunas ideas sobre diseño e implementación de políticas diferenciadas para el desarrollo rural que sería largo detallar aquí. cados, ya sea porque éstos no existen o porque los costos de transacción ${ }^{6}$ asociados con el acceso a ellos son tan elevados que resulta más ventajoso para los agentes realizar transacciones a través de arreglos institucionales distintos al mercado. Esta característica da lugar a formas institucionales y de relaciones entre agentes cuyo particularismo las distingue de los mecanismos institucionales más formales en los mercados indicados. Como se destaca más adelante, con frecuencia el surgimiento de distintas formas de articulación entre los pequeños productores y otros agentes surge como respuesta a la inexistencia o ineficacia de uno o más mercados.

A título de ejemplo, mencionaremos los obstáculos que enfrentan los pequeños productores con recursos potenciales para explotar cultivos de mayor valor.

i) Crédito. Mientras los granos básicos pueden ser cultivados con una densidad de insumos concordante

${ }^{6}$ Más adelante se hace referencia al concepto de costos de transacción. 
con los recursos financieros de la familia campesina, los cultivos comerciales exigen casi siempre un gasto en insumos e incluso en mano de obra adicional que excede por mucho las disponibilidades de la unidad y constituye una barrera formidable para pasar a rubros de mayor valor, ${ }^{7}$ aun si la actividad a que se habrían dedicado hubiese podido justificar con creces el crédito requerido.

ii) Seguro. Se señaló anteriormente que los pequeños productores internalizan el riesgo en forma distinta a la que es propia de la mediana y gran empresa. Los primeros necesitan buscar fórmulas que reduzcan los riesgos derivados de asumir la producción de rubros no tradicionales, dado que éstos implican mayores costos directos, más susceptibilidad a factores que afectan la calidad o el rendimiento y mayores fluctuaciones de precios, y además no tienen valor de uso directo en el consumo familiar. Como no existe la opción de asegurarlos, los pequeños productores deben recurrir a diversos mecanismos para enfrentar los riesgos, como la venta de activos (ganado), la entrega de tierra en arrendamiento, la diversificación de cultivos, la opción por cultivos menos sujetos a fluctuaciones aunque generen menos ingresos, el trabajo extrapredial, la emigración y los acuerdos con compradores.

iii) Información. El acceso a la información sobre opciones tecnológicas, tipos de productos demandados en términos de calidades y precios, canales alternativos de intermediación, restricciones en el uso de ciertos insumos y otros aspectos, es cada vez más determinante del éxito de un actividad. Sólo el segmento de productores modernos suele disponer de estos antecedentes que constituyen el dominio de empresas agroindustriales. El carácter segmentado de los mercados de información hace que sea el comprador o intermediario el vehículo que la lleva hacia los pequeños productores, pues implica costos de adquisición que escapan a sus posibilidades, e incluso, salvo excepciones, a las de sus cooperativas.

iv) Tecnología e insumos especializados. El mercado para varios de los insumos o servicios que se utilizan en los cultivos no tradicionales es por lo general demasiado estrecho, de modo que el acceso a él para los pequeños productores pasa por alguna forma de acuerdo o asociación con la agroindustria o el agrocomercio. Así se hace, por ejemplo, ante las nue-

\footnotetext{
${ }^{7}$ Los costos por hectárea de muchos de los cultivos no tradicionales pueden llegar a ser 10 o más veces mayores que los de los granos básicos.
}

vas variedades de semillas o plántulas, las cambiantes exigencias en materia de agroquímicos o las nuevas tecnologías de conservación y embalaje.

v) Tierra. El mercado de tierras sigue siendo muy rígido para ajustar demanda y oferta; durante largo tiempo estuvo sujeto a restricciones legales, incluso en los países en que no se efectuaron reformas agrarias de alguna significación. En los últimos años se han ido relajando estas restricciones con la explícita intención de impulsar el desarrollo de dicho mercado; sin embargo, el mayor o menor dinamismo de éste ha estado más sujeto a consideraciones especulativas que a su valor como recurso productivo. En los predios pequeños que los propietarios se resisten a vender o arrendar surgen mecanismos sustitutivos de la compra o el arriendo para permitir el inicio o expansión de una determinada actividad, como son las distintas formas de agricultura de contrato. ${ }^{8}$

vi) Mano de obra. El mercado de mano de obra en el campo tiene particularidades que emanan del carácter multiactivo de los pequeños productores, que permite salarios menores para actividades homólogas a las urbanas; del aislamiento o dispersión en que se hallan respecto a los medios de transporte, lo que limita su movilidad; de la naturaleza estacional de la actividad agrícola, que por requerir flexibilidad impide la ampliación de empleos permanentes; de ciertas formas de intermediación (el enganche) que restan transparencia a la remuneración recibida y de la falta de información sobre oportunidades existentes, entre otros factores. ${ }^{9}$

En relación con las fallas de mercado, un documento reciente de FAO (1997) junto con examinar las implicaciones para la agricultura de los cambios en el entorno macroeconómico, señala algunas opciones de políticas sectoriales compatibles con el mercado y de mecanismos de transición hasta ponerlas en vigencia, como las bandas de precios, la promoción de exportaciones, las transferencias de ingreso a pequeños productores (en reemplazo de subsidios a la producción) o la promoción de la agricultura de contrato como respuesta a uno o más de los problemas de mercado que se han descrito.

\footnotetext{
${ }^{8}$ Véase al respecto Schetjman, 1998. Otra de las consecuencias de las rigideces de este mercado es la de acotar los alcances de los procesos de redistribución a favor de los pequeños productores vía mercado, como las iniciadas en Brasil y Colombia.

9 Véase un análisis más detallado de estos mercados en Figueroa (1998, pp. 96-104).
} 


\section{c) Los costos de transacción}

Los costos de transacción son aquellos en que un agente tiene que incurrir, por encima del precio del bien o servicio que adquiere, para tratar de asegurarse de que éste corresponda a sus expectativas; incluye, por lo tanto, los costos de búsqueda, información y supervisión, y el de asegurar cumplimiento. Según Sadoulet y De Janvry (1995, pp. 255-256), si en los intercambios '...existen incentivos para comportamientos oportunistas de las partes que pueden resultar en selección adversa o riesgo moral, evitarlos tiene altos costos. Lo primero implica costos ex ante de preselección de candidatos y lo segundo costos ex post de seguimiento, acciones legales e imposición de cumplimiento.'

Las fallas de mercado y sus efectos en los costos de transacción constituyen, por una parte, fenómenos exógenos a la unidad familiar, entendidos como barreras estructurales a su acceso a ciertos mercados; por otra, pasan a ser determinantes endógenos de las decisiones de venta o autoconsumo o de empleo externo o autoempleo cuando exista una brecha — generada por los costos de transacción- que haga que el precio de compra supere al de venta, o que la productividad neta supere al salario más los costos de transacción de acceder al empleo extrapredial, respectivamente. ${ }^{10} \mathrm{De}$ igual modo, puede entenderse que se opte por crédito informal en lugar del bancario, aun cuando éste sea accesible a tasas de interés menores que la del informal, si los costos de transacción para adquirir el crédito bancario, sumados a la tasa, superan al costo del crédito informal.

Según Benedicty, ${ }^{11}$ la "reducción de la brecha de precios se logra disminuyendo los costos específicos de transacción que enfrenta la unidad. Si esta presunción es verosímil, debemos reconocer de inmediato que sabemos muy poco acerca de la estructura de los costos de transacción. Debemos reconocer, asimismo, que el enfoque convencional, esto es, modelos que postulan una estructura de tasas de interés efectivas, tasas de arrendamiento de tierras y salarios que sólo varían como función del tamaño de la granja, en el mejor de los casos son sólo aproximaciones abstractas. Es necesario hacer un esfuerzo urgente para acopiar información a nivel de unidad familiar sobre la estructura y determinantes de los costos de transacción, tarea que es ciertamente un desafío a enfrentar".

Las fallas de mercado o los costos de transacción dan lugar a "transacciones articuladas" que permiten soslayar estos problemas mediante intercambios en que los accesos a un producto, a un servicio, a mano de obra o a alguna forma de seguro pasan a integrarse en una sola operación, ${ }^{12}$ en claro contraste con la interdependencia anónima y sistémica de la actividad económica (en mercados competitivos propios) que postula la teoría del equilibrio general (Bardhan, 1991, p. 237).

Sin perjuicio de que se puedan intuir, en términos muy genéricos, las fallas de mercado y de gobierno que se traducen en costos de transacción para la agricultura familiar, sus manifestaciones concretas tienen características locales, por lo que su detección y eventual superación deben plantearse a esa escala. Las formulaciones generales son sólo orientaciones para focalizar los ámbitos de observación, pero es el análisis a escala local de la naturaleza y magnitud específica de sus implicaciones el que puede constituir una guía para la acción.

\section{II}

\section{Los enfoques tradicionales del desarrollo rural}

\section{Principales limitaciones}

Entendiendo por políticas o estrategias de desarrollo rural el conjunto de acciones orientadas a mejorar las condiciones de vida y de trabajo de la población rural, en particular de los pequeños productores y de los

\footnotetext{
${ }^{10}$ No cabe aquí desarrollar el fundamento teórico de lo señalado. Al respecto véase Sadoulet y De Janvry (1995, pp. 149-159).

${ }^{11} \mathrm{M}$. de Benedicty, en un comentario a la primera versión de este trabajo.
}

trabajadores con poca o ninguna tierra, es posible advertir una serie de limitaciones en los enfoques tradi-

\footnotetext{
${ }^{12}$ Con frecuencia, la falta o imperfección de determinados mercados para los pequeños productores se "resuelve" con complejos arreglos entre agentes, como lo ilustra la producción del tomate en el Valle de Ica en Perú, donde la agroindustria arrienda tierras de campesinos que trabajan en ellas por cuenta de la empresa. Para el campesino, el salario reemplaza la falta de crédito para sus cultivos, que unida a la falta de acceso a la tecnología y al seguro, le impide asumir la producción del tomate; para la empresa, el arriendo condicionado permite soslayar las rigideces del mercado de tierras y de trabajo (CEPAL, 1996b).
} 
cionales de dichas estrategias que se señalan a continuación.

i) Hacen caso omiso del alto grado de heterogeneidad que caracteriza al mundo de la pequeña agricultura y, por lo tanto, de la necesidad de políticas diferenciadas por tipo de productor, que sólo recientemente y de manera muy parcial han empezado a ser adoptadas explícitamente por algunos países de la región.

ii) Están centradas en la actividad agrícola, sin tener en cuenta el carácter multiactivo de las unidades familiares, a pesar de la importancia que ha adquirido el trabajo extrapredial para el funcionamiento mismo de la actividad agrícola, como fuente importante de ingresos complementarios y como componente de los mecanismos para enfrentar los riesgos inherentes a la producción agrícola; ${ }^{13}$ y particularmente, sin asumir la importancia que ha ido adquiriendo el empleo rural no agrícola, al que haremos referencia más adelante.

iii) No intervienen, o lo hacen sólo de manera fragmentaria o esporádica, para corregir (o más bien sustituir y no siempre con éxito) las fallas o inexistencias de mercado frecuentes en el ámbito de los pequeños productores (respecto a información, tecnología, mercados de insumos y de productos, y crédito seguro).

iv) No consideran, salvo excepciones, la producción agrícola en el contexto de sus vínculos con otros agentes de la cadena producción primaria-transformación agroindustrial-comercialización, desaprovechando entre otras cosas la posibilidad de inducir a la agroindustria a desempeñar el papel de difusor de tecnología hacia determinados segmentos del sector de pequeños productores. ${ }^{14}$

v) Carecen de capacidad, a nivel de los gobiernos locales, para adecuar las propuestas estratégicas o las políticas que se gestan centralmente a las potencialidades y restricciones específicas de cada localidad.

vi) En un sentido más amplio, no consideran los efectos potenciales, en la transformación productiva de

\footnotetext{
13 En un estudio sobre el Ecuador se estimó que los ingresos no provenientes de la producción agrícola representaban entre el $80 \%$ para los campesinos con menos de una hectárea y un 30\% para los que tenían entre 5 y 20 ha (De Janvry y Glikman, 1991), y en otro para México, se estimó que en promedio el ingreso extrapredial era de un $36 \%$, variando entre un $58 \%$ para campesinos con menos de 2 ha y un 24\% para los que tenían más de 18 ha (De Janvry, Gordillo y Sadoulet, 1997).

14 Véase al respecto la serie de trabajos sobre Agroindustria y Transformación Productiva de la Pequeña Agricultura que fueron elaborados en virtud del convenio CEPAL/FAO/GTZ para varios países de la región, y que aparecen sintetizados en Schejtman (1998) y CEPAL (1996a).
}

la actividad agrícola y en las condiciones de vida y de trabajo de la población rural, de un determinado desarrollo de los vínculos con los núcleos urbanos con los que interactúan los pequeños productores y pobladores rurales. ${ }^{15}$ Una excepción la constituyen los trabajos recientes de Paniagua (1994 y 1997) sobre Bolivia y Perú, respectivamente, y de Riordan (1997) sobre Perú, que muestran las potencialidades de un enfoque de este tipo para el desarrollo rural y el alivio de la pobreza.

\section{Migración y desarrollo rural}

Con frecuencia, uno de los objetivos explícitos o implícitos del desarrollo rural ha sido el de "evitar la migración rural-urbana" con fundamentos que, en sus versiones más ideologizadas, satanizan el mundo urbano e idealizan el rural, y en las más "objetivas", se fundan en consideraciones de costo y beneficio social.

Los procesos de hiperurbanización que caracterizaron a la mayoría de los países de la región a partir de los años cincuenta han podido tal vez justificar el sesgo antimigratorio de muchas propuestas de desarrollo rural. Pero esto no ha impedido que los cambios en la distribución espacial de la población —en que el peso relativo de lo agrícola rural disminuye- han seguido y seguirán una tendencia "natural" que sólo medidas de fuerza o políticas conservadoras de alto costo pueden impedir. ${ }^{16}$ Admitido el hecho de que persistirán los procesos migratorios campo-ciudad, la cuestión central pasa a ser qué tipo de estímulos es necesario generar para que esos flujos se reorienten en un sentido favorable al desarrollo rural.

Conviene en este sentido mencionar, aunque sea de manera telegráfica, algunos de los efectos positivos de las migraciones sobre el desarrollo rural, por su

\footnotetext{
15 Incluso las estrategias del llamado desarrollo rural integral se han circunscrito a la actividad de los pequeños productores en su calidad de trabajadores agrícolas y sólo a los vínculos que, en cuanto tales, tienen con su entorno; en los trabajos sobre "estrategias de sobrevivencia", aunque se incorpora lo urbano en el análisis de las opciones de empleo e ingreso, el examen de las potencialidades de la referida articulación queda reducido a ese ámbito.

16 En general, una parte no despreciable del "agrarismo", tanto en sus versiones más populistas o campesinistas como en las desarrollistas, de modo implícito o explícito justificaba, al menos en parte, sus propuestas como destinadas a frenar los procesos migratorios del campo a la ciudad, sin reconocer que "la emigración rural es uno de los elementos constitutivos del desarrollo económico: es necesaria, es obligatoria y es positiva. Si la población excedentaria no migrara del campo sería imposible introducir el proceso de modernización..." (Vergara, 1992, p. 184).
} 
eventual contribución, directa o indirecta, a los ingresos de las familias, la transformación productiva de la pequeña agricultura y la superación de la pobreza y de los problemas de deterioro ambiental:

i) Con relación a los ingresos, porque quien migra lo hace en general en pos de mejores oportunidades de ingreso que las que la actividad agrícola le ofrecía; en este sentido, la afirmación frecuente de que el migrante termina por sumarse a la masa de desocupados urbanos no parece sostenerse empíricamente, como lo confirman antecedentes de varias ciudades latinoamericanas. ${ }^{17}$

ii) En lo que se refiere a la transformación productiva, porque ayuda al proceso de modernización agrícola en varios sentidos. Primero porque, ceteris paribus, eleva la productividad de los que permanecen al mejorar la relación de superficie por persona activa - siempre que quienes migran no constituyan la fuerza de trabajo más productiva y queden sólo niños y ancianos-, y en algunas circunstancias puede mejorar la asignación de recursos. Segundo, porque, como lo prueban muchas experiencias de cambio en el ámbito de la pequeña agricultura, son los migrantes quienes suelen inducir dichos cambios al traer información e ideas que sólo en el entorno urbano es posible adquirir. Tercero, porque, sobre todo en las zonas de muy pequeñas propiedades, donde son muy limitadas las posibilidades de intensificar el trabajo, la migración puede ser una condición de sobrevivencia, contribuyendo incluso a subsidiar la actividad agrícola con ingresos extraprediales. Y cuarto, porque los ingresos extraprediales pueden contribuir a superar (o por lo menos a morigerar) dos de las dificultades que enfrenta la pequeña producción para adoptar innovaciones accesibles: la falta de un excedente para sufragar los costos y la imposibilidad de asumir los riesgos que toda innovación supone.

iii) En relación con la pobreza, se observa que en casi todos los países de la región el grado de ruralidad de un municipio o localidad suele estar altamente correlacionado con los niveles de pobreza, y que, por ende, el tamaño de la familia y la tasa de dependencia son más altos en el sector rural que en el urbano, y también es mayor la brecha entre la fertilidad real y la deseada, como revelan encuestas al respecto. ${ }^{18}$

iv) En cuanto a los problemas ambientales, es un hecho conocido que la explotación más intensiva en áreas con pendientes pronunciadas, la presión por deforestar zonas de frontera y la intensificación de los cultivos en áreas de secano o temporal, son mayores mientras mayor sea la relación hombre/tierra, dando lugar a diversos procesos de deterioro ambiental. Por otra parte, las migraciones hacia las grandes urbes generan también problemas ambientales. Estimaciones hechas por Jeffrey y otros (1989) indicarían que el $80 \%$ de los pobres de América Latina vive en áreas urbanas o rurales de alta vulnerabilidad ecológica, y un 24\% en áreas urbanas. ${ }^{19}$

Hechos estos alcances sobre migración, desarrollo rural y pobreza, queda en evidencia la necesidad de ubicar estos dos últimos aspectos en un marco más amplio que el estrictamente agrícola o el estrechamente rural.

\section{III}

\section{La cuestión urbana yel desarrollo rural}

El paradigma clásico sobre el papel de la agricultura en los procesos de desarrollo (à la Johnston y Mellor) se centraba en los aportes esperados de la agricultura al desarrollo en general y al urbano-industrial en par-

\footnotetext{
17 Estimaciones hechas a fines de los años sesenta indican que en Lima y varias ciudades de Colombia las tasas de desempleo de los migrantes eran bajas e inferiores a las de los no migrantes. En Santiago de Chile, la tasa de desocupación entre los migrantes varones era de $4.6 \%$, y de $7.2 \%$ entre los nativos. En Ciudad de México, aunque pocos habían arreglado un empleo antes de migrar, $46 \%$ encontró trabajo a la semana, otro $30 \%$ al mes, y dos tercios de ellos experimentaron importantes mejoras de ingreso.
}

\footnotetext{
18 Una serie de encuestas demográficas y de salud practicadas en varios países indican que: "el nivel de fecundidad deseada por las familias es inferior en casi un $40 \%$ a su fecundidad efectiva..."; la brecha entre la fecundidad efectiva y la deseada es mayor mientras más bajo es el nivel socioeconómico de la familia, indicando, por una parte, la existencia de un margen no despreciable de reducción del crecimiento de la pobreza y, por otra, la necesidad de diseñar métodos de difusión más eficientes que las alternativas existentes para aproximar la fecundidad deseada a la efectiva. Por otra parte, $80 \%$ de las madres adolescentes en las zonas urbanas y $70 \%$ en las rurales pertenecen al 50\% de los hogares más pobres (CEPAL, 1998, pp. 114-125).

${ }_{19}$ Véase en Lipton (1980, pp. 1-24) una visión crítica de los efectos de la migración, que hace hincapié en sus efectos sobre la distribución del ingreso entre familias de una localidad y que contrasta con la aquí presentada.
} 
ticular, y destacaba que éstos incluían la transferencia del campo a la ciudad de ahorro, fuerza de trabajo, alimentos, divisas, etc. Raras veces se ha formulado la pregunta inversa, es decir, cuál podría o debería ser la contribución del desarrollo urbano al desarrollo agrícola; a estas alturas parece prudente plantear que, por una parte, la disparidad de desarrollo entre las metrópolis y los espacios rurales, cualquiera sea su definición, es en extremo grave y no muestra visos de reducirse y, por otra, que el acelerado incremento de los vínculos entre lo rural y lo urbano empieza a desdibujar los límites entre ellos (Da Silva, 1998).

Esta prolongada ausencia, en la formulación de las políticas, de un cuestionamiento sobre el papel que podría tener el núcleo urbano en el desarrollo de su entorno rural, se dio aunque en los estudios de historia económica o agraria, al examinar los vínculos entre la formación y desarrollo de los núcleos urbanoindustriales y el desarrollo agrario, se destacaba que aquellos países de industrialización temprana o tardía con estructuras agrarias relativamente homogéneas habían experimentado en las fases iniciales de la industrialización círculos virtuosos de demandas recíprocas entre la agricultura y la industria. Al inicio, dichas demandas correspondieron a bienes simples de consumo y de producción por parte de una masa relativamente homogénea de pequeños y medianos productores agrícolas, que indujo al surtimiento interno de empresas manufactureras destinadas a satisfacerla; el desarrollo de estas últimas generó, a su vez, una demanda creciente de alimentos e insumos agrícolas, dando lugar a una sofisticación cada vez mayor de los patrones de consumo y las técnicas de producción, así como, last but not least, al surgimiento de una vasta camada de empresarios (Jones y Woolf, 1969).

La dinámica indicada contrasta, en cada uno de sus aspectos, con la de sociedades que en los inicios de la industrialización tuvieron su espacio rural dominado por la hacienda o la plantación, por sus efectos sobre la distribución del poder, los patrones de acumulación, el sesgo en los senderos de cambio tecnológico y las limitaciones para generar una masa crítica de capacidad empresarial (Schejtman, 1997, p. 127).

Sin duda, los trabajos de Hirschman (1961) sobre encadenamientos hacia adelante y hacia atrás y los de Myrdal (1962) sobre causación circular, constituyen fuentes inescapables para examinar los vínculos entre el desarrollo urbano y su entorno rural. Por otra parte, la propuesta de Evans (1992) de un modelo de "círculo virtuoso" de desarrollo urbano-rural es precisamente una réplica a microescala del proceso mencio- nado; pero, sin perjuicio de sus aciertos, la debilidad principal de esta propuesta es no considerar que la inducción de dicho proceso no se da a partir de cero o en un marco de estructuras agrarias homogéneas, sino, por el contrario, en un contexto de estructuras productivas y sociales altamente diferenciadas.

Otro tema ausente, vinculado con el anterior, ha sido el de las consideraciones sobre el espacio o territorio en el que se desarrolla la actividad económica. Según observa Krugman (1997, p. viii), a pesar de ser éste un tema de obvia importancia práctica, ha estado completamente ausente del corpus estándar de la teoría económica y, nos permitimos agregar, de nuestras propias reflexiones. ${ }^{20} \mathrm{El}$ mismo autor (ibid, p. 41) señala que los modelos espaciales de actividad económica (que tuvieron su inicio en los estudios de Von Thünen de principios del siglo pasado, orientados a explicar la formación de la renta de la tierra en función de la distancia de un núcleo urbano), así como los trabajos de Christaller de principios del siglo presente sobre los "lugares centrales", destinados a analizar la localización de manufacturas y mercados con respecto a una determinada población agrícola homogénea, pasaron inadvertidos en la literatura económica dominante hasta avanzados los años cincuenta. Sin embargo, su influencia en la geografía económica y en la llamada ciencia regional ha sido innegable y fue rescatada por Krugman en lo que se ha dado en llamar la "nueva geografía económica” (Renkow, 1998).

\section{Desarrollo urbano y transformación rural}

En los últimos años se ha ido dando un debate en el ámbito de la ciencia regional entre la propuesta denominada de integración funcional (I/F) y la de localización-asignación (A-L), que se ha centrado básicamente en las metodologías para establecer la localización de servicios e infraestructura en núcleos urbanos que puedan servir de inductores del desarrollo rural. Aunque no corresponde examinar aquí dichas formulaciones, ${ }^{21}$ diremos que, mientras la segunda toma como criterio la demanda actual o potencial y no incorpora los problemas derivados de la desigual distribución de

\footnotetext{
${ }^{20}$ Carlos Franco reprochaba a los investigadores de los problemas del campo “...el reducido número, ....de las (investigaciones) orientadas a vincular 'la cuestión agraria' con la migración, la urbanización, las microrregiones ...el sector informal urbano..." (Franco, 1992, p. 395).

21 Véase al respecto la serie de artículos aparecidos en la International Regional Science Review (1992 a y b), y también Belsky y Karaska (1990, pp. 225-240).
} 
los ingresos, la primera apunta a generar encadenamientos desde el núcleo urbano hacia el entorno rural mediante la oferta de servicios e infraestructura, partiendo de la noción de que los problemas de desarrollo espacial polarizado en la mayoría de los países en desarrollo fueron la consecuencia de sesgos en la distribución de las inversiones nacionales, por lo que su solución requerirá también de sesgos en favor de núcleos urbanos secundarios (Rondinelli, citado por Hansen, 1990).

El enfoque de integración funcional está más próximo al problema de fortalecer las articulaciones positivas entre los pequeños núcleos urbanos y el entorno rural, pero si no se considera la heterogeneidad de la estructura productiva del sector agrícola la aplicación de esta metodología no asegura que sus beneficios sean accesibles a los pequeños productores, a menos que las características de los servicios y de la infraestructura se definan a partir de las restricciones o carencias que dichos productores enfrentan. Así lo plantean, por ejemplo, Johnston y Kilby (1975) en su excelente trabajo sobre agricultura y transformación estructural, que explora los contrastes en los desarrollos a partir de estructuras agrarias bimodales y unimodales.

Hay, sin embargo, amplia coincidencia entre diversos analistas en sostener que el fortalecimiento urbano-industrial beneficia el desarrollo agrícola, señalando que las ciudades han constituido un punto importante de origen y de difusión de la tecnología agrícola (Jacobs, 1970); que los mercados de capital, de insumos, de trabajo y de productos tienden a ser menos imperfectos en el entorno de núcleos urbano-industriales, y que como derrame, la agricultura adyacente puede disfrutar de mayor mecanización, menos trabajo excedente, mejores precios para sus productos y por ende de mejor remuneración de su trabajo (Schultz, 1953; Katzman, 1974).

Según Schultz, i) el desarrollo económico se da (habitualmente) en una matriz de localización específica y puede haber una o más de tales matrices en una economía en particular; ii) la composición de estas matrices de localización es primariamente de tipo urbano-industrial, como centros en los cuales parte el desarrollo económico, y no normalmente de tipo rural o agrícola, aun cuando algunas áreas agrícolas están situadas mejor que otras en relación con estos centros, y iii) la organización económica existente funciona mejor en el centro de la matriz de desarrollo o cerca de él y en aquellas áreas de la agricultura cuya ubicación es más favorable en relación con ese centro; funciona menos bien en las áreas situadas en la periferia de la matriz (citado por Bhadra y Salazar Brandao, 1993).

En una estimación hecha para el estado de São Paulo de la correlación entre el valor agregado per cápita en la manufactura y ciertos cambios en la estructura agrícola, se comprueba, para dos períodos, que tal correlación es positiva con el porcentaje de tierra arable utilizada, el número de tractores más camionetas, el uso de fertilizantes y pesticidas por hectárea, la densidad de maquinaria por trabajador y la producción por hectárea y por trabajador; en cambio, la correlación es negativa o neutra con la tierra por trabajador (es decir, ésta no parece afectar el grado de concentración).

Por su parte, Vergara (1992, p. 190) muestra el vínculo entre ruralidad y modernización agrícola para el Perú en una estratificación de comunas (cuadro 2).

\section{El empleo rural no agrícola}

\section{a) Magnitud y significado}

A nuestro entender, el primero de los trabajos destinados a examinar la magnitud y características del empleo rural no agrícola (ERNA) ${ }^{22}$ en América Latina es el elaborado por Klein (1992) para el Programa Regional del Empleo para América Latina y el Caribe (PREALC) de la Organización Internacional del Trabajo. En él se muestra que, en los años ochenta y en casi todos los países, el ERNA habría crecido a ritmos significativamente mayores que el empleo propiamente agrícola. En efecto, mientras este último aumentó $0.8 \%$ al año, el primero subió $3.4 \%$, tasa superior incluso a la del crecimiento de la población económicamente activa (PEA) en la región. Al respecto, según indica Klein (ibid, p. 2) se observa que en 12 de los 18 países para los cuales existe información el empleo rural no agrícola aumenta más rápidamente que el empleo total y en ocho países aumenta incluso más rápidamente que el empleo urbano ${ }^{23}$ (gráfico 1). Refiriéndose a la estructura del ERNA, Klein destaca que ésta es similar a la del mercado de trabajo urbano no agrícola, específicamente en cuanto a la importancia relativa de cada sector de actividad (ibid, p. 7).

\footnotetext{
${ }^{22} \mathrm{El}$ empleo rural no agrícola corresponde a residentes rurales que trabajan en actividades distintas a la agrícola (comercio, construcción, industria, servicios y otras) y el urbano agrícola a residentes urbanos empleados en actividades agropecuarias en el área rural.

${ }^{23}$ Salvo en Bolivia (el empleo agrícola subió al $1.8 \%$ y el rural no agrícola al 1\%) y Uruguay, en que ambos cayeron, pero bajó más el rural no agrícola.
} 


\begin{tabular}{|c|c|c|c|c|c|}
\hline & $\begin{array}{l}\text { Hectáreas } \\
\text { per cápita }\end{array}$ & $\begin{array}{c}\text { Mecanización } \\
\%\end{array}$ & $\begin{array}{c}\text { Fertilización } \\
\%\end{array}$ & $\begin{array}{c}\text { PEA agrícola } \\
\%\end{array}$ & $\begin{array}{c}\text { Poblacción rural } \\
\%\end{array}$ \\
\hline Estrato I & 0.52 & 1 & 11 & 77 & 80 \\
\hline Estrato II & 0.77 & 4 & 16 & 64 & 65 \\
\hline Estrato III & 1.13 & 21 & 36 & 35 & 29 \\
\hline Estrato IV & 1.83 & 46 & 32 & 6 & 4 \\
\hline
\end{tabular}

Fuente: Vergara, (1992).

GRAFICO 1

Tasas de crecimiento del empleo rural en América Latina a mediados de los años ochenta

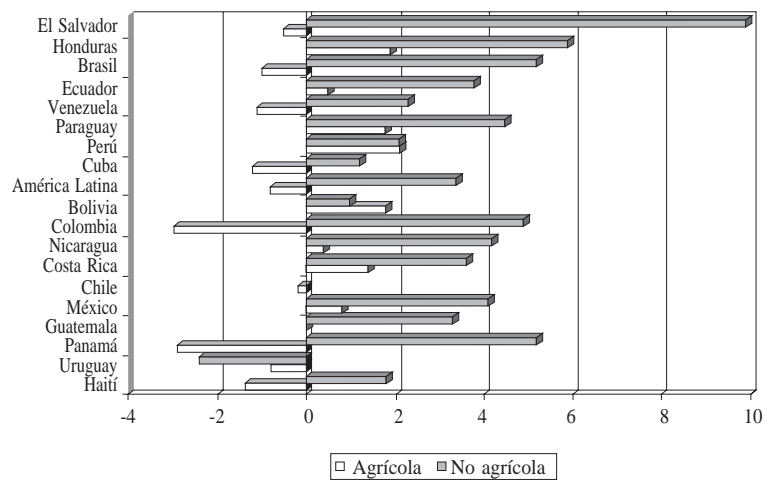

Fuente: Klein (1992).

Informaciones más recientes sobre varios países no hacen sino confirmar las tendencias mencionadas en la región: Da Silva (1998, p. 19) señala que, en el período 1992/1995 la PEA rural en Brasil aumentó en casi 200 mil personas, mientras que la propiamente agrícola disminuyó en cerca de 250 mil, lo que implica que en dicho período el ERNA absorbió a casi 550 mil personas. Más aún, el autor destaca que mientras el ERNA creció al 1.2\% annual en los años ochenta, en la primera mitad de los noventa casi triplicó dicha tasa al alcanzar un crecimiento anual del $3.5 \%$; por contraste, la PEA ocupada en actividades agrícolas, que crecía en los ochenta cerca de $1 \%$ por año, disminuyó en los noventa a una tasa de $4.5 \%$ anual (ibid, pág. 23). En términos de la estructura ocupacional del ERNA, los resultados coinciden con los observados por Klein.

Escobal (1996), en tabulaciones realizadas a partir de la encuesta de hogares de 1994, muestra que en el sector rural del Perú cerca de un tercio de las jornadas de trabajo en las actividades principal y secundaria se dedica a labores no agropecuarias que tienden a decrecer a medida que aumenta la superficie disponible para familias con menos de 5 hectáreas, y a incrementarse a medida que aumentan los niveles de educación promedio de los miembros del hogar. Por otra parte, dos tercios de las jornadas de trabajo del $8 \%$ de los hogares rurales de no productores — que incluyen seguramente un heterogéneo conjunto de trabajadores y empleados - estarían dedicadas a actividades no agropecuarias.

De Janvry, Gordillo y Sadoulet (1997), en un estudio muestral sobre hogares en el sector reformado (ejidal) de México, estimaron que para las unidades más pequeñas ( menores de 2 hectáreas) el ingreso por actividades extraprediales llegaba al $82 \%$ del total, con casi un $48 \%$ derivado de salarios y de microempresas. En las unidades más grandes dichos ingresos alcanzaban casi al $45 \%$. La migración era vital para los productores más pequeños, pues representaba casi un tercio de su ingreso total. La comparación de los resultados obtenidos para la muestra en 1994 y 1997 (sólo tres años de diferencia) mostraban una tendencia al incremento del peso relativo de los ingresos no agrícolas, en particular los de autoempleo y de microempresas. A partir de esta información Lanjouw (1998, p.20) estima que, para un determinado tamaño de unidad familiar, mientras más miembros están en empleos no agrícolas, menor es la probabilidad que la familia caiga en situación de pobreza.

Para El Salvador, el Banco Mundial (1997) estimó que aproximadamente el 36\% de la PEA rural está empleada en actividades no agrícolas, cifra que casi dobla la registrada a mediados de los años setenta. En el caso de las mujeres, el ERNA llega a cerca del 72\% (Banco Mundial, 1997, p .9, viii). La estructura del ERNA confirma una vez más lo señalado por Klein, pues muestra casi un $30 \%$ empleado en diversas manufacturas, un $20 \%$ en construcción, un $23 \%$ en comercio y transporte, un $22 \%$ en servicios de baja calificación y un $5 \%$ en los de mayor calificación. El estudio del Banco Mundial concluye que las familias menos po- 
bres en las áreas rurales son las que tienen importante acceso a empleos no agrícolas, que el acceso a mejores empleos está fuertemente ligado a los niveles educativos y que los servicios de infraestructura influyen de modo importante en la oferta de ERNA.

Para el Ecuador, Lanjouw (1998) estima que a mediados de los años noventa más del $40 \%$ del ingreso de los hogares rurales provenía de actividades no agrícolas, en las que las microempresas tenían una importante participación: generaban casi 900 mil empleos, cifra cercana al $60 \%$ de la fuerza de trabajo rural del país. Por lo demás, existía una clara correlación entre los niveles de ingreso de las familias y el porcentaje de éste que proviene del ERNA, dentro del cual el originado en microempresas hacía la mayor contribución; tales microempresas tenían, en promedio 1.8 personas ocupadas y más del $60 \%$ estaban radicadas en el propio hogar de los productores (ibid, p. 16). Al igual que en los casos anteriores, los niveles de educación constituían un determinante clave de la probabilidad de operar una microempresa, y el acceso a energía eléctrica y a teléfono constituían factores coadyuvantes a la gestación de este tipo de unidades.

En síntesis, el ERNA tiene un peso importante y cada vez mayor en la absorción de fuerza de trabajo rural; es un mecanismo de superación de la pobreza que la sola actividad agrícola no ofrece; permite estabilizar los ingresos, compensando la estacionalidad de la producción y del empleo agrícola; y permite diversificar las fuentes de ingreso, reduciendo los efectos de los riesgos inherentes a la agricultura. El acceso a mejores opciones de ERNA está fuertemente vinculado a los niveles de educación, al desarrollo de infraestructura (energía, caminos, teléfonos) y al género, ${ }^{24}$ pues los hombres acceden a actividades mejor remuneradas que las mujeres.

\section{b) Factores determinantes del desarrollo del ERNA}

Los mercados que es necesario considerar al examinar los vínculos urbano-rurales en general y los de la estructura y características del ERNA en particular son: el de trabajo, el de capital, el de productos y el de insumos, incluidos los aspectos relativos a la información y a los riesgos involucrados en participar en ellos.

En efecto, según Renkow (1998), estos mercados circunscriben "la cancha" sobre la cual se establecen los vínculos rural-urbanos; dentro de ésta, las "reglas

\footnotetext{
${ }^{24}$ En relación con la pobreza cabe agregar que la educación de las mujeres y su acceso a opciones de ERNA reducen los niveles de fecundidad, acercando la deseada a la real.
}

del juego" que determinan la localización de las unidades productivas serían las economías de escala en la producción, la estructura de la demanda (y economías pecuniarias externas relacionadas), y el costo de la distancia; cabría esperar entonces que las empresas no agrícolas produzcan a menor escala mientras mayor sea su distancia económica de los centros urbanos de gravedad, que abarca tanto la distancia física como el rango de los costos de transacción negociados a través de los mercado que mencionamos antes.

En un reciente trabajo, Reardon (1998) analiza los factores determinantes del nivel y la composición del ERNA a través de una serie de hechos estilizados que corresponden grosso modo a las condiciones de varios países en desarrollo y que, en términos muy esquemáticos, podemos representar en el gráfico 2, cuyo desarrollo argumental escapa a los propósitos de este trabajo.

\section{El enfoque de la articulación urbano-rural}

Nadie pone en duda que la hiperurbanización tiene implicaciones no deseables y que es correcto plantear estrategias que reduzcan o morigeren su crecimiento. Pero si la hipótesis de que el desarrollo urbano estimula o en determinadas circunstancias puede estimular el desarrollo rural, lo que cabe es examinar de modo crítico si el actual patrón de poblamiento urbano contribuye efectivamente a promover este desarrollo ${ }^{25}$ ó, dicho en sentido positivo, qué medidas es necesario impulsar para que los potenciales efectos benéficos se materialicen.

Reexaminar los problemas del desarrollo rural supone insertarlos en el marco del desarrollo de las economías locales, es decir, hacer hincapié en las articulaciones económicas entre el núcleo urbano y su hinterland agrícola, analizando cómo se entrelazan a esa escala los distintos mercados, fragmentarios o no. Sólo así pueden abordarse los temas de transformación productiva y también los de pobreza y medio ambiente con la especificidad requerida para poder asegurar

\footnotetext{
${ }^{25}$ Refiriéndose a Perú, Vergara (1992, p. 186) señala al respecto: "en realidad la gran catástrofe migratoria de la región [fue que] los campesinos de la Sierra no migraron hacia sus ciudades sino hacia las de la costa. En consecuencia, el efecto modernizador que genera la urbanización fue monopolizado por la costa. Las rentas de localización favorecieron a los campesinos costeños y no a los serranos; la oferta de los servicios existió para los costeños y no para los serranos; la modernización de las mentalidades, de las relaciones sociales de producción y de la tecnología fue ajena al espacio andino. Sin ciudades, el espacio andino vegetó en el pasado."
} 


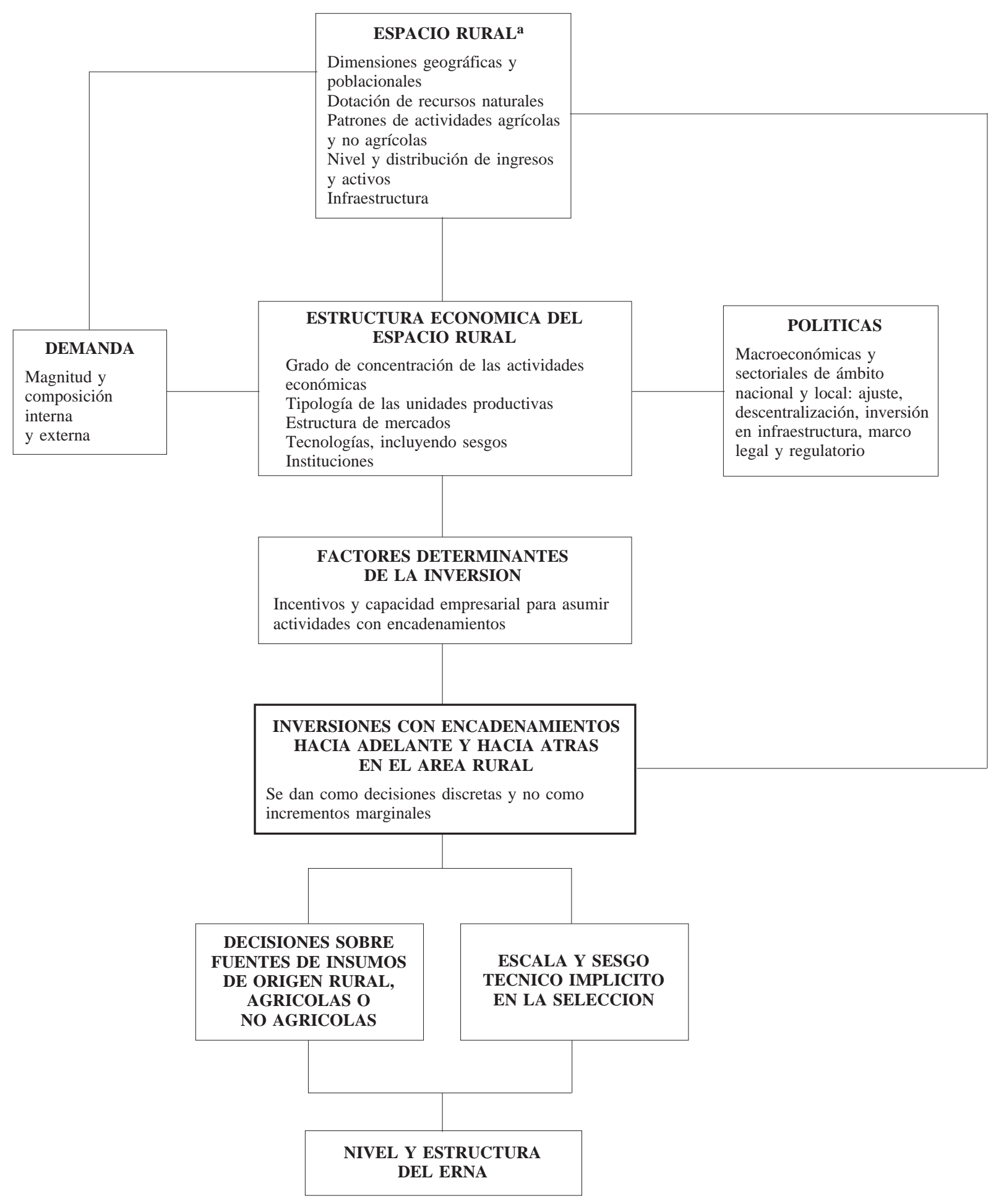

a Sólo excluye las grandes ciudades. 
eficacia y participación en un marco institucional determinado al que se hace referencia más adelante.

Se espera que un enfoque de esta índole sirva para: i) entender el funcionamiento de la economía local como una articulación de mercados, detectar sus fallas, sus ausencias y los mecanismos formales e informales para llenar dichos vacíos; ii) formular, a partir de dicho conocimiento, políticas que induzcan la gestación de círculos virtuosos de demandas recíprocas entre el núcleo urbano y su hinterland agrícola en un amplio espectro de actividades; iii) descubrir o corregir los cuellos de botella existentes en las cadenas de producción-distribución o la ausencia de eslabones críticos que puedan introducirse a partir de incentivos específicos, e iv) impulsar el desarrollo de estructuras institucionales de nivel local que sean funcionales al desarrollo de dichos círculos virtuosos, rompiendo la compartimentación característica de la organización del sector público para aprovechar las sinergias de acciones en los ámbitos de la infraestructura, la transferencia tecnológica, la salud, educación, la vivienda, la microempresa.

\section{IV}

\section{Innovación institucional, descentralización y participación}

La heterogeneidad estructural del agro, las características de los mercados rurales, las diferencias en materia de potencialidades y de restricciones que caracterizan a los distintos espacios rurales, y las particularidades de sus vínculos con núcleos urbanos de distinto tipo, plantean la necesidad de aplicar un enfoque territorial del desarrollo rural. Esto implica propiciar cambios institucionales que eleven la eficacia de la acción pública en dicho ámbito, con medidas que apunten de manera más precisa a tener en cuenta las potencialidades, demandas y restricciones cuya especificidad sólo puede percibirse a escala local. ${ }^{26}$

Los procesos de descentralización y de desconcentración de recursos, que han pasado a formar parte de las políticas de la mayoría de los países de la región, ${ }^{27}$ constituyen un primer paso en la dirección de los cambios institucionales requeridos; sin embargo, en

\footnotetext{
${ }^{26}$ Por instituciones se entiende no sólo las vinculadas al aparato público sino el conjunto de reglas de comportamiento que moldean o estructuran la interacción social. El concepto incluye tanto las de tipo formal (leyes, reglamentos, contratos) como las de tipo informal (costumbres, valores compartidos, convenciones tácitas). Su rasgo común es que 'implican reglas que delimitan los comportamientos en un determinado dominio, dando lugar a regularidades en el comportamiento" de los agentes' (Yifu y Nugent, 1995, p. 2307). En lo que sigue, sin embargo, nos concentraremos en aquellas iniciativas de cambio de la institucionalidad pública capaces de generar cambios en la interacción público-privada.

${ }^{27}$ Cabe mencionar a Chile, Colombia, México, Perú y Venezuela que han establecido procesos de cierta envergadura, y a Bolivia que dictó en 1994 la Ley de Participación Popular y al año siguiente la Ley de Descentralización.
}

muchos casos el carácter compartimentado de las funciones públicas a nivel central tiende a reproducirse a escala municipal, con el agravante de que los niveles de formación de los cuadros técnicos suelen no estar a la altura de la tarea de elevar la eficiencia y la eficacia de los mayores recursos públicos que se han puesto a su alcance. ${ }^{28}$

Tanto la compartimentación como el insuficiente nivel técnico constituyen obstáculos para aprovechar las potencialidades que encierra el fortalecimiento de los vínculos entre las ciudades medianas y su hinterland agrario.

\section{Desarrollo de la institucionalidad local}

El fortalecimiento de la capacidad de gestión de los poderes locales para avanzar en una política participativa a la escala de la economía local, constituye la principal tarea en el ámbito del desarrollo institucional, dado que a nivel local: i) es posible percibir, con mucha mayor precisión, la especificidad de las carencias, restricciones y potencialidades de su desarrollo; ii) las posibilidades de convertir en un "recurso" la participación organizada de la población afectada (o si se quiere el "capital social") requiere de "ámbitos terri-

\footnotetext{
${ }^{28}$ Von Haldenwanh (1997) hace un sugerente análisis sobre los vínculos entre el proceso de descentralización en América Latina y la fase del ajuste estructural, destacando los elementos de eficacia y los de legitimación.
} 
toriales reducidos e interlocutores institucionales muy próximos" (Borja, 1987, p. 56), y iii) las posibilidades de control social —para el sostenimiento o la reorientación de la política- por parte de quienes se suponen destinatarios de la acción pública son mucho más viables.

La creación de condiciones para una gestión participativa se apoya en tres componentes interrelacionados: la introducción de cambios en la organización del aparato público con miras a fortalecer la articulación urbano-rural; el estímulo al desarrollo y fortalecimiento de la organización de la población del núcleo urbano y del hinterland, eventuales beneficiarios de dichas políticas, y la necesidad de dotar a la nueva organización de equipamiento que permita la interacción de los agentes públicos de distinto nivel, tanto entre sí como con las organizaciones de la población local.

En la población, debería estimularse la creación y fortalecimiento de organizaciones homogéneas y representativas a nivel local. La homogeneidad de los organizados debe ser tal, que los intereses que los muevan y los problemas que enfrenten tengan un grado razonable de semejanza, para evitar formas espurias de representación.

En lo que se refiere al aparato público, debería asegurarse el sostenimiento del proceso de descentralización de la gestión pública, de desconcentración de los recursos (humanos, materiales y financieros), de integración a nivel local de las funciones (normalmente dispersas y fragmentadas) que exhiben potenciales sinergias, y de capacitación de los funcionarios locales.

En cuanto al equipamiento, una vez creadas las bases organizativas, ${ }^{29}$ es necesario avanzar en la dotación de los equipos necesarios para establecer una red interactiva de información/comunicación que vincule la localidad al municipio, éste a la región, y la región al centro administrativo. Así se podrán aprovechar las denominadas tecnologías de información - término referido a la integración de la microelectrónica con la telecomunicación y los computadores-, cuyo costo ha bajado espectacularmente en las últimas décadas. ${ }^{30}$

\footnotetext{
29 Aunque sea de modo embrionario, pero dotándolas de flexibilidad suficiente para posibilitar su modificación posterior en función de la experiencia.

${ }^{30} \mathrm{El}$ costo de la capacidad de procesamiento y de computación ha declinado a una tasa continua de $30 \%$ anual en términos reales en las últimas tres décadas. Por contraste, uno de los bienes más afectados por el progreso técnico en la primera revolución industrial, las telas de algodón, cayeron aproximadamente $3.4 \%$ por año desde fines del siglo XVIII hasta principios del XIX (OCDE, 1988, p. 37).
}

Cabe señalar que la utilización de la Internet como herramienta para el desarrollo rural ha comenzado en más de algún país (véase FAO, 1997).

\section{Nueva institucionalidad y economía local}

La comprensión de las potencialidades y restricciones de la economía local y de las demandas y capacidades de su población en un contexto institucional como el señalado, permitirían entre otras cosas:

i) abordar los problemas de pobreza, de inseguridad alimentaria y de deterioro ambiental local, apuntando con mayor precisión a la naturaleza de las carencias más sentidas y de las restricciones más críticas;

ii) generar y movilizar el ahorro local para orientarlo hacia proyectos locales; ${ }^{31}$

iii) generar proyectos de inversión en infraestructura productiva y social para romper los cuellos de botella que limitan la conformación de círculos virtuosos urbano-rurales;

iv) integrar mercados fragmentados al fortalecer las redes de los mercados regionales, en especial los mercados mayoristas que simplifican el proceso de juntar a compradores y vendedores en un mismo espacio, reduciendo los costos de transacción (PNUD/ CNUAH, 1995);

v) dar contenido específico a la naturaleza de las necesidades de capacitación y de avance tecnológico tanto en el ámbito agrícola como entre las pequeñas industrias locales, con frecuencia incipientes;

vi) hacer accesible la información, sobre todo la que ayuda a mejorar las estrategias para obtener empleo e ingresos, pues la ausencia o deficiencia de la información contribuyen a la mala asignación de los recursos y a perder o no advertir oportunidades existentes. Este aspecto tiene particular importancia si se considera, como se indicó más atrás, la gravitación que tiene el trabajo extrapredial en la economía familiar;

vii) satisfacer demandas específicas sobre los problemas ambientales que afectan a la localidad, y

viii) constituir el espacio adecuado para que participe la sociedad civil y para que los agentes públicos rindan cuenta a la población a la que sirven.

Sin perjuicio de que las ventajas descritas se consideren razonables, carecemos de propuestas de vali-

\footnotetext{
${ }^{31}$ En muchos países de la región las remesas de quienes salieron a trabajar fuera de su localidad e incluso al extranjero son una fuente de recursos no despreciable que podría canalizarse en sistemas locales de ahorro.
} 
dez general respecto a cómo gestar, en cada realidad particular, procesos de cambio institucional que aseguren en alguna medida los efectos deseados. Parece haber acuerdo entre los diversos autores sobre algunas de las condiciones básicas que deben cumplirse para que el proceso de descentralización satisfaga las expectativas. Entre ellas destacan la existencia de autoridades elegidas democráticamente, de una sociedad civil con organizaciones representativas y de condiciones de transparencia en la gestión pública que impidan el clientelismo, la corrupción y el rentismo. Aunque es improbable que el conjunto de estas condiciones se dé en forma absoluta, no es menos cierto que mientras más alejada de ellas esté la realidad concreta de cada país, más improbable será que la descentralización, si se adopta, cumpla con los objetivos de desarrollo rural.

En general, por paradójico que parezca, en la fase actual de desarrollo democrático de muchos países latinoamericanos, el gobierno central desempeña un papel clave en la descentralización. Esto no sólo porque para que ésta se lleve a cabo el gobierno, como es obvio, deberá delegar parte de su poder en entidades subnacionales y en organizaciones de la sociedad civil, sino porque además deberá impedir la malversación de fondos, evitar que las prioridades sean fijadas por un reducido núcleo de poderosos e inhibir el derroche en iniciativas sin sentido de funcionarios locales inexpertos o corruptos. ${ }^{32}$ En ocasiones, el gobierno central debe presionar desde la base de las entidades subnacionales a sus gobiernos locales para gestar procesos de real descentralización participativa, como lo destacan los estudios de caso analizados por Tendler: 'En la medida en que los casos de Ceará suponían descentralización, revelaban algo muy diferente a los procesos de transferencia unidireccional del poder central al local que está en el corazón de la caracterización estilizada de la descentralización. Sorprendentemente, el gobierno central quitó poder al gobierno local aun cuando sus acciones contribuyeron, en último término, a fortalecer la capacidad del poder local' (Tendler, 1997, pp. 146-147).

\footnotetext{
32 Hommes (1995, p. 337) señala que: 'La Constitución de Colombia establece que una porción de los ingresos corrientes están destinados a los departamentos y que éstos deben compartir un porcentaje de dichos recursos con las municipalidades. La ley regula el uso de dichos fondos asignando porcentajes fijos a las distintas funciones. Algunos críticos sostienen que los controles del sistema son excesivos pues limitan la descentralización. La rigidez de los controles puede, sin embargo, prevenir la malversación de fondos, e inhibir el derroche en iniciativas sin sentido por funcionarios locales inexpertos o corruptos.'
}

\section{La falta de vías de descentralización prees- tablecidas}

Por último, nos referiremos a la dificultad de establecer reglas generales que hagan más o menos viable la gestación de estructuras descentralizadas y participativas. De Benedicty destacaba, con justa razón, ${ }^{33}$ que, a pesar del reconocimiento creciente en la literatura económica de la importancia de las instituciones, los resultados de las investigaciones no permiten pasar del nivel del análisis — cómo surgieron determinadas instituciones y qué impacto económico y social tuvieronal nivel normativo de establecer para una realidad dada las formas específicas de la matriz institucional que asegure el logro de determinados objetivos económicos y sociales.

En otras palabras, no es posible establecer a priori la mecánica por la cual se gesta y desarrolla un proceso satisfactorio de descentralización, ni el grado en que se delegan o no determinadas atribuciones en aspectos como el establecimiento y captación de tributos, la autonomía en el gasto, las inversiones y proyectos de determinación local, las regulaciones ambientales, las de comercio y transporte, etc. ${ }^{34}$ No en vano entre las conclusiones de una reciente Consulta sobre Descentralización se señalaba que en la medida en que la descentralización depende de muchos factores nacionales y locales como el marco legal, el régimen político, la densidad de la sociedad civil, el grado de cohesión nacional, y otros, no existe una sola vía para descentralizar; se debe, por lo tanto, estar prevenido contra modelos simplistas y predicciones inequívocas respecto de las vías y los efectos de la descentralización. $^{35}$

Sin perjuicio de lo anterior, la mayor o menor viabilidad de un proceso de descentralización participativa para un área o región determinada parece depender del grado de concentración del hábitat, del grado de homogeneidad de los grupos sociales, de sus nive-

\footnotetext{
${ }^{33}$ Comentario manuscrito a una primera versión de este documento.

34 Ver al respecto la crítica a la descentralización fiscal de Prud’homme, así como los artículos de Prud’homme, de Tanzi, de Oates y de Hommes, en Banco Mundial (1995).

${ }^{35}$ Los estudios de caso examinados por Tendler (1997) muestran las limitaciones de los enfoques simplistas que suponen que descentralización y participación se condicionan mutua y necesariamente, y ponen en evidencia la necesidad de cuestionar algunos supuestos sobre el gobierno central, la sociedad civil y las organizaciones no gubernamentales, sugiriendo a la vez una dinámica de tres vías (local, central y cívica) en lugar de la unidireccional de las propuestas convencionales.
} 
les de organización, y de la calidad y cobertura de la infraestructura. En general, el proceso será más viable en hábitat concentrados, con población relativamente homogénea y organizada y con un grado razonable de infraestructura local, y tropezará con grandes dificultades, si es que llega a funcionar, en hábitat dispersos y poblaciones heterogéneas, no organizadas y carentes de infraestructura.

Bibliografía

Banco Mundial (1995): Annual Bank Conference on Development Economics 1995, Washington, D.C.

(1997): El Salvador Rural Development Study: Main Report vol.2, Washington, D.C.

Belsky, E. y G. Karaska (1990): Approaches in locating urban functions in developing rural areas. International Regional Science Review, $\mathrm{N}^{\circ} 13$, Morgantown, West Virginia, West Virginia University, Regional Research Institute.

Bardhan P. (ed.) (1991): The Economic Theory of Agrarian Institutions, Clarendon Paper Backs, Oxford University Press.

Bhadra, D. y A. Salazar Brandao (1993): Urbanization, Agricultural Development and Land Allocation. World Bank discussion papers, $\mathrm{N}^{\circ}$ 201, Washington, D.C., Banco Mundial.

Borja, J. (1987): Descentralización del Estado, movimientos sociales y gestión local, Santiago de Chile, Instituto de Cooperación Iberoamericana (ICI)/Facultad Latinoamericana de Ciencias Sociales (FLACSO).

CEPAL (Comisión Económica para América Latina y el Caribe) (1982): Economía campesina y agricultura empresarial (tipología de productores del agro mexicano), México, D.F., Siglo Veintiuno Editores, S.A.

(1990): Transformación productiva con equidad, LC/G.1601-P, Santiago de Chile. Publicación de las Naciones Unidas, $\mathrm{N}^{\circ}$ de venta S.90.II.G.6.

(1992): Equidad y transformación productiva: el enfoque integrado LC/G.1701/SES.23/3, Santiago de Chile, agosto. Publicación de las Naciones Unidas, $\mathrm{N}^{\circ}$ de venta: S.92.II.G.5. (1996a): Agroindustria y pequeña agricultura: síntesis comparativa de distintas experiencias, Santiago de Chile.

(1996b): Pequeña agricultura y agroindustria en el Perú, Santiago de Chile.

(1998): Panorama social de América Latina 1997, LC/G.1982-P, Santiago de Chile.

Cruz, M.E. (1997): Llay Llay: Una ciudad intermedia del Chile Central, Documento de consultoría, Santiago de Chile, Organización de las Naciones Unidas para la Agricultura y la Alimentación (FAO).

Da Silva, J.G. (1998): Novo rural brasileiro, São Paulo, Brasil, Universidad Estadual de Campinas, Instituto de Economía.

De Janvry, A. y P. Glikman (1991): Encadenamientos de producción en la economía campesina en el Ecuador, San José, Costa Rica, Fondo Internacional de Desarrollo Agrícola/ Instituto Interamericano de Cooperación para la Agricultura (FIDA/IICA), septiembre

De Janvry, A., G. Gordillo y E. Sadoulet (1997): Mexico's Second Agrarian Reform, La Jolla, San Diego, University of California, Center for U.S.-Mexican Studies.

Escobal, J. (1996): Diferenciación campesina y políticas diferenciadas, trabajo presentado al Taller Latinoamericano de Políticas Diferenciadas y Tipologías Agrarias, Santiago de Chile, 20 al 24 de mayo.

Evans, H. E. (1992): A virtouous circle model of rural-urban development: Evidence from Kenya, The Journal of Development Studies, vol.28, ํㅜ 4, Londres, Frank Cass Co. Ltd.
Fajnzylber, F. (1991): Inserción Internacional e innovación institucional, Revista de la CEPAL, N 44, LC/G.1667-P, Santiago de Chile, CEPAL.

Fajnzylber, F. y A. Schejtman (1995): Agricultura, industria y transformación productiva. América Latina a fines de siglo. México, D.F., Fondo de Cultura Económica.

FAO (Organización de las Naciones Unidas para el Alimentación y la Agricultura) (1997): Internet y el desarrollo rural y agrícola: un enfoque integrado, Departamento de Desarrollo Sostenible, Roma.

Figueroa, A. (1981): La economía campesina en la Sierra del Perú, Lima, Pontificia Universidad Católica del Perú.

(1998): Pobreza rural en los países andinos, L. Reca y R. Echeverría (comps.), Agricultura, medio ambiente y pobreza rural en América Latina, Washington, D.C., Instituto Internacional de Investigaciones sobre Políticas Alimentarias/ Banco Interamericano de Desarrollo.

Franco, C. (1992): La investigación agraria: argumentando un reproche, Debate agrario, $\mathrm{N}^{\circ} 13$, Lima, Centro Peruano de Estudios Sociales (CEPES).

Hansen, N. (1990): Impacts of small and intermediate sized cities on population distribution: Issues and responses, Regional Development Dialogue, vol. 11, N 1, Nagoya, Japón, Centro de las Naciones Unidas para el Desarrollo Regional.

Hirschman, A.O. (1961): La estrategia del desarrollo económico, México, D.F., Fondo de Cultura Económica.

Hommes, R. (1995): Conflicts and dilemmas of decentralization, en Annual World Bank Conference on Development Economics 1995, Washington, D.C., Banco Mundial.

International Regional Science Review (1992a): vol.14, Morgantown, West Virginia, West Virginia University, Regional Research Institute.

(1992b): vol.15, Morgantown, West Virginia, West Virginia University, Regional Research Institute.

Jacobs, J.(1970): The Economy of Cities, Londres, Random House.

Jeffrey, H. y otros (1989): Environment and the poor: Development strategies for a common agenda, U.S.-Third World Policy Perspectives, $\mathrm{N}^{\circ} 11$, Washington, D.C., Consejo de Desarrollo de Ultramar.

Jones, E.L. y S.J. Wolf (1969): Agrarian Change and Economic Development, Londres, Methuen \& Co. Ltd.

Johnston, B. y P. Kilby (1975): Agriculture and Structural Transformation: Economic Strategies in Late Developed Countries, Londres, Oxford University Press.

Katzman M.(1974): The Von Thünen paradigm, the industrial-urban hypothesis and the spatial structure of agriculture, American Journal of Agricultural Economics, vol. 56, pp. 863-696, San Francisco, California, American Agriculture Economic Association (AAEA)

Klein, E. (1992): El empleo rural no agrícola en América Latina, Investigaciones sobre empleo, $\mathrm{N}^{\circ} 364$, Santiago de Chile, Programa Regional del Empleo para América Latina y el Caribe (PREALC).

Krugman, P. (1997): Development, Geography and Economic Theory, Cambridge, Massachusetts, The MIT Press. 
Lanjouw, P. (1998): Rural non-farm employment and poverty: Evidence from household survey data in Latin America, trabajo presentado al IFPRI Workshop on Strategies for Stimulating Growth of the Rural Non-Farm Economy, Washington, D.C., Instituto Internacional de Investigaciones sobre Políticas Alimentarias.

Lipton, M. (1968): The theory of the optimizing peasant, The Journal of Development Studies, vol. 4, N 3, Londres, Frank Cass \& Co. Ltd.

(1980): Migration from rural areas of poor countries: the impact on rural productivity and income distribution, World Development, vol. 18, pp. 1-24.

Mertins, G. (1995): La diferenciación socio-espacial y funcional de las ciudades intermedias latinoamericanas: ejemplos del noroeste argentino, Revista interamericana de planificación, vol. 28, $\mathrm{N}^{\circ} 112$, Cuenca, Ecuador, Órgano de la Sociedad Interamericana de Planificación.

Myrdal, G. (1962): Teoría económica y regiones subdesarrolladas, México, D.F. Fondo de Cultura Económica.

Oates, W.E. (1995): Comments on "Conflicts and dilemmas of decentralization" by Rudolph Hommes, en Annual World Bank Conference on Development Economics 1995, Washington, D.C.,Banco Mundial.

OCDE (Organización de Cooperación y Desarrollo Económicos) (1988): New Technologies in 1990's. A Socio-Economic Strategy, París.

Ortega, L. (1998): Desarrollo agrícola asociado a ciudades intermedias, Documento de consultoría, El Salvador, PNUD.

Paniagua, A. (1994): Desarrollo agrícola asociado a ciudades intermedias en agroindustria y pequeña agricultura, La Paz, FAO/Instituto Latinoamericano de Investigaciones Sociales (ILDIS).

(1997): Análisis complementario del proyecto de desarrollo del corredor Puno-Cusco, Documento. de cosultoría, Lima, Corporación Financiera de Desarrollo.

Pearse, A. (1984): Seeds of Plenty, Seeds of Wants, Ginebra, Instituto de Investigación de las Naciones Unidas para el Desarrollo Social.

PNUD/CNUAH (Programa de las Naciones Unidas para el Desarrollo/ Conferencia de las Naciones Unidas sobre Asentamientos Humanos-Habitat) (1995): Rural-urban Linkages: Policy Guidelines for Rural Development.

Prud'homme, R. (1995): Comments on "Conflicts and dilemmas of decentralization" by Rudolph Hommes, en Annual World Bank Conference on Development Economics 1995, Washington, D.C., Banco Mundial.

Renkow, M. (1998): Cities, towns and the rural non farm economy, trabajo presentado al IFPRI, Workshop on Strategies for Stimulating Growth of the Rural Non-Farm Economy, Was- hington, D.C., Instituto Internacional de Investigaciones sobre Políticas Alimentarias.

Riordan, J. (1997): Elementos para el desarrollo de las ciudades intermedias en apoyo a la lucha contra la pobreza extrema, Lima, Perú, Ministerio de la Presidencia.

Reardon,T. (1998): Agroindustrialization in intermediate cities in Latin America: hypotheses regarding employment effects on the rural poor, trabajo presentado al IFPRI Workshop on Strategies for Stimulating Growth of the Rural Non-Farm Economy, Washington, D.C., Instituto Internacional de Investigaciones sobre Políticas Alimentarias.

Rondinelli, D. (1990): Locational planning and regional economic development: Appropriate methods in developing countries, International Regional Science Review, $\mathrm{N}^{\circ} 13$, Morgantown, West Virginia, West Virginia University, Regional Research Institute.

Sadoulet, E. y A. De Janvry (1995): Quantitative Development Policy Analysis, Baltimore, Pennsylvania, Johns Hopkins University Press.

Schejtman, A. (1980): Economía campesina: lógica interna, articulación y persistencia. Revista de la CEPAL. $\mathrm{N}^{\circ} 11$, Santiago de Chile, CEPAL. Publicación de las Naciones Unidas, $\mathrm{N}^{\circ}$ de venta S.80.II.G.3..

(1997): Peasants and structural adjustment in Latin America, S. Lindberg y A. Sverrisson (eds.), Social Movements in Development: The Challenge of Globalization and Democratization, Londres, Mac Millan Press, Ltd.

(1998): Agroindustria y pequeña agricultura. Experiencias y opciones de transformación, CEPAL/Sociedad Alemana de Cooperación Técnica (GTZ)/FAO, Agroindustria y pequeña agricultura: vínculos, potencialidades y oportunidades comerciales, Santiago de Chile.

Schultz, T. (1953): The Economic Organization of Agriculture, Nueva York, McGraw Hill.

Tanzi, V. (1995): Fiscal federalism and decentralization: A review of some efficiency and macroeconomic aspects, Annual World Bank Conference on Development Economics 1995, Washington, D.C., Banco Mundial.

Tendler, J. (1997): Good Government in the Tropics, Baltimore, Pennsylvania, Johns Hopkins University Press.

Vergara, R. (1992): La ciudad y el campo ¿una danza eterna?, Debate agrario, $\mathrm{N}^{\circ} 13$, Lima, CEPES.

Von Haldenwang, Ch.(1997): Descentralización, fases de ajuste y legitimación, Diálogo científico, vol. $6, \mathrm{~N}^{\circ} 72$, Tübingen, Alemania, Instituto de Colaboración Científica.

Yifu J. y J. Nugent (1995): Institutions and economic development, en J. Behrman y T.N. Srivanasan (eds.), Handbook of Development Economics, vol. 3, Amsterdam, Países Bajos, Elsevier Science Publishers, B.V. 